\title{
数字化测绘技术在地质工程测量中的应用分析探讨
}

\author{
谷大鹏 \\ 第四地质大队有限责任公司 \\ DOI:10.32629/gmsm.v3i2.567
}

[摘要] 随着科学技术水平的进一步提高, 大数据技术已被广泛应用于各行业之中。将大数据引入到地质工程中后, 实现了地质工程事业的快 速发展。数字化测绘技术的兴起极大改善了地质工程测量的工作效率, 实现了地质工程测量质的飞跃。

[关键词] 数字化测绘技术; 地质工程测量; 应用

现今在地质工程测量工作中, 已逐渐引入了多种类型的新兴科技。尤 其在地质测量的实际应用环节, 采用了较多与地质测量工作相适应的新技 术, 有效改变了过去传统技术的弊端, 保障了地质测量工程的精准性。其中 数字化测绘技术作为应用最为广泛、实际效果最佳的新技术, 得到了越来 越多的关注度。此项技术的应用有效解决了地质工程测量中的诸多弊端, 提高了工作效率, 实现了地质工程的建设速度。

\section{1 数字化测绘技术的构成}

数字化测绘技术主要包括全球定位系统 (GPS) 、地理信息系统 (GIS)、遥感技术 (RS), 应用这些各具特点的技术可极大提升数字化测绘 技术的发展。

1. 1 GPS

GPS为一种基于卫星导航定位功能的技术, 可实现对目标的精准定位。 GPS系统主要包括地面监控系统、空间卫星及接收设备。将GPS应用于测绘 工作中, 能够测量出各类物体之间的距离。随着技术的发展, 现已在此基础 上开发出了实时动态差分技术 (RTK), 进一步提高了定位的精准度, 使其能 够达到厘米级别。

1.2 GIS

GIS技术实现了地理空间分析及数据整合功能, 利用了三个坐标轴将 空间位置进行准确定位, 具有操作简便、可靠性强的优点, 在地质工程测量 工作中得到了广泛应用。GIS具有强大的数据分析能力, 还可以依据各种不 同的数据表达方法, 利用图表的方式将数据资料直观化。其中, 三维仿真地 图可通过多媒体形式将数据进行形象展示。

1. 3 RS

此外, 在规划阶段, 要贯彻落实以人为本的理念, 根据经济发展需求与 学科特点, 征集相关单位的意见, 再选定领域内的专家进行具体推敲, 之后 面向社会实行项目的建议征集, 反馈给分领域专家, 最终得到新的实施方 案, 且借助信息平台完善规划流程管理。

\section{3 新时期国土空间规划的对策}

3.1 充分发挥国土空间规划的综合性

鉴于国土空间规划自身具有的引导性和统领性作用, 其综合性特征越 发明显, 在国土空间规划开展中, 应高效发挥综合性特征, 以期强化规划和 管理的效果, 促进社会的建设和发展。

3. 2 健全相关法律体系

国土空间规划工作的开展, 需要完善的法律体系作为支撑, 因此应健 全现有的法律条文, 实现不同层级的科学管理, 这样才能更好的提升规划 工作中各部门及人员的协调效率, 实现统筹管理和控制。对于省级、市级 等层面, 需要形成由上而下相互对应的规划法规体系, 保证城乡规划、土地 规划等的法律效力, 避免出现违法用地现象。
$\mathrm{RS}$ 利用了传感器探测物体的电磁场信息, 并将此类信息进行转化, 使 其能够直观的表达出所需资料。RS技术可分为物理场遥感技术、声学遥感 技术、电磁波遥感技术, 可实现对微波的接收, 并向着多波段、全程动态监 测方向发展。

通过上述分析可以看出三种测量技术各有其特点, 并且有自身显著地 不足之处。因此在经过一段时期的发展后, 已逐渐形成了能够综合运用的 3S技术, 实现空间定位、获取地理信息、综合分析的全方位应用模式。

\section{2 数字化测绘技术在地质工程测量中的应用优势}

2. 1 精准度较高

数字化测绘技术中会应用到较多仪器设备, 这些经过精密设计的现代 化设备结合了现今的各种技术, 从而极大保证了测量结果的精确度及稳定 性。在开展地质工程测量工作时, 会深入到地质结构一线, 因野外环境较为 恶劣, 如采用传统测量方式, 必然会受到多重因素的共同影响, 致使测量结 果难以保证。采用数字化测绘技术后, 可实现测绘数据的自动化采集和准 确定位, 且精准度较高。因全过程均是在自动化控制系统下完成, 因此较少 受到各种因素影响, 从而确保所采集数据的精确度, 促进地质工程测量的 进步。

2.2自动化程度高

数字化测绘主要依据计算机技术及信息技术, 能够将干扰因素降至最 低限度。如在信息录入环节中, 以往均需依靠人工完成相应工作, 采取了数 字化测绘技术后, 可极大促进测绘数据的精确度及工作效率。只需将测量 得到的数据录入到工作软件中即可实现各项信息的分析比对, 同时将各种 相关信息自动匹配, 从而确保工程绘图的完整性及准确性。

\section{3 实现资源整合}

在国土空间规划中, 需做好其他规划的细致分析, 了解其他规划工作 的内涵及标准要求, 并从中找出共同点, 做好资源的整合利用, 以此改善国 土空间规划水平。

\section{4 结语}

新时期, 国土空间规划的内涵及作用也得到了进一步的提升, 相关部 门有必要加大协调力度, 建立完善的法律体系, 且促进与不同规划工作的 整合, 以此达到国土空间规划目标, 落实我国整体建设要求。

\section{[参考文献]}

[1]苏世亮,吕再扬,王伟,等.国土空间规划实施评估:概念框架与指标 体系构建[J].地理信息世界,2019,26(04):20-23.

[2]李升发,陈伟莲,张虹鸥.关于我国空间规划用地分类的思考 [J].城 市与区域规划研究,2017,9(04):59-71.

[3]杨莹.以国土空间规划构想破解历史文化名城的发展问题[J].智库 时代,2019,(51):3-4. 
2. 3资料存储方便

由于测绘工作要应用到大量数据资料, 因此在传统测绘工作中会产生 较多的纸质文件。应用纸质文件不但不利于环保, 并且较易丢失或损坏。采 用数字化测绘技术后, 可实现将数据存储到各种电子设备中。不仅能够提 高工作效率, 并且还可以减少相应的测量成本, 从而提升经济效益。

2.4缩短制图时间

采用数字化测绘技术后, 应用各种软件可以实现对数据资料的快速分 析, 并能够辅助工作人员完成制图工作。很大程度上提高了制图效率, 减轻 了工作负担。同时采用计算机进行制图时, 还能够在制图过程中实时进行 快速修改, 相比传统手工绘制更加方便快捷。据统计, 应用数字化测绘技术 可比传统测绘方式提升 5 倍的工作效率。

\section{3 数字化测绘技术在地质工程测量中的应用}

3. 1 地质勘查

载波相位差分技术 (RTK) 在地质测量中应用较广泛, 它可以通过基站 将采集到的载波相位传输到接收设备上, 同时将其进行求差解算坐标, 实 现了野外地质工程测量的准确度, 可做到厘米级的精确定位。由于此项技 术定位精准度高, 因此RTK技术的应用效率及使用效果极佳。

\section{2 原图数字化}

为使地质工程测量各项数据得到充分利用, 应将其进行原图数字化处 理。在进行原图数字化处理时, 通常采用扫描矢量化及手动跟踪数字化方 法。由于二者具备不同的应用优势, 要根据实际需求确定相应方案。其中 扫描矢量化的工作效率较高, 但会产生原图分辨率下降等情况, 从而影响 图形的正常使用, 因此矢量化扫描技术一般应用于较为紧急的情况下。另 外手动跟踪数字化技术工作效率较低, 可通过后续与补测及修测技术结合 使用, 并应用扫描矢量化做配合, 从而提高原图的精确度。

3.3 GPS在地质工程测量中的应用

GPS作为数字化测量技术的代表, 对地质工程测量的精准度有着极大 影响。要重视GPS的应用, 使其能够发挥出应有的效果。首先要在测量站点 中安装好GPS接收设备, 从而实现对地质状况的实时监测。GPS接收设备会 自动寻找工程卫星, 并将所获取到的资料传输至移动站点, 通过做进一步 分析, 能够得到高精度的位置信息。

3. 4 构建数字地球体系

随着计算机技术的飞速发展, 基于互联网理念的数字地球概念应运而 生。数字地球不仅集合了人类各项科技成果, 并且能够实现科技与社会之 间的有机融合, 并对设定的地面坐标进行有效管理。由此可见, 数字地球是 一项综合系统性工程, 其中包含了社会、经济、地理、科技等一系列因素, 因此在构建的过程中需要各个领域开展共同协作。数字化测绘技术的应用, 为构建数字地球提供了丰富资料, 并可以对各项数据进行判断, 从而保障 了数据信息的准确度。数字地球体系在地质工程测量工作中发挥了巨大作 用, 能够极大简化工作流程, 提高工作效率, 并将各项数据进行资源共享, 有效保障了相关方向的科技研发速度。
3. 5 数字化成像技术

在进行地质工程测量时需要较为精确的测量结果, 并与测绘结束后绘 制成地质勘探结构图。由于对制图要求较低, 从而致使图纸中的相关微小 数据方面出现一定纰漏。而应用到数字化成像技术后, 能够大幅提升图像 的精准度及测量的全面性。全站仪是数字化成像技术中应用最为广泛的新 型技术, 全站仪能够实现一次性观测, 并获取到丰富的资料, 如可以显示出 被测物体的直角距离及水平距离。全站仪可将测绘所得数据进行自动计算 分析, 并将计算结果展示出来, 供技术人员作参考。由于其具备自动性能, 使得相应的人工操作大幅减少, 从而杜绝了因人工操作所造成的计算结果 偏差问题。

\section{4 提升数字化测绘技术在地质工程测量中的应用策略分析}

数字化测绘技术的应用能够极大带动我国地质工程测量事业的发展, 为更为充分的利用此项技术, 应制定出相应的发展策略, 保证数字化测绘 技术持续稳定的发展。

4. 1 加强对技术人员的培训力度

由于数字化测量方法具有较强的技术性, 因此应重视对从业人员的技 术培训。首先, 数字化测绘技术的应用基础为计算机技术, 这其中包含了众 多相关软件, 技术人员需充分掌握这些软件的使用方法。通过开展相应的 培训工作, 促进自身专业素质的提升, 实现测绘工作的顺利开展。除需学习 设备的操作方法之外, 还应对设备检修及保养有所了解。要严格落实持证 上岗制度, 确保工作人员具备相应的处理能力。

4.2 重视操作设备的日常检验工作

在开展地质工程测量时, 应首先做好各种仪器设备的检验及校正工 作。由于数字化测绘工作对精准度的要求极高, 因此仪器设备一旦出现故 障将会严重影响到测绘结果。工作人员应在每次开展测量工作前均对设备 进行全面检查, 如发现设备故障, 应及时排除故障并分析故障产生的原因。

\section{5 结语}

数字化测绘技术的发展成熟极大改善了工程测绘中的各种问题, 具有 自动化程度高且性能极佳的特点, 现已广泛应用于地质勘查及各种测绘工 作之中。数字测绘技术的出现, 提升了工程测量的速度及精确性, 实现了对 传统工程测量技术的有效弥补, 并建立起完整的数字化测绘理论体系。另 外在应用数字化测绘技术的过程中, 要重视对相关人才的培养, 做好各项 设备使用时的准备工作, 从而保障最终测量结果的精准性。

[参考文献]

[1]方立林. 数字化测绘技术在地质工程测量中的应用分析[J]. 石化技 术,2019,26(11):197+195.

[2]蔡晓,谢晓明. 数字化测绘技术在地质工程测量中的应用分析探讨 [J].科技展望,2017,(16):57.

[3]李良园. 数字化测绘技术在工程测量中的应用分析 [J]. 居 舍,2018,(26):226. 